\title{
Prevalence rates and cardiometabolic determinants of diabetes mellitus and pre-diabetes with projected coronary heart disease at bank site of Brazzaville
}

\author{
Gombet Thierry ${ }^{1}$, Longo-Mbenza Benjamin ${ }^{2 *}$, Ellenga-Mbolla Bertrand ${ }^{1}$, Ikama M. Stephan ${ }^{3}$, \\ Kimbally-Kaky Gisèle ${ }^{3}$, Nkoua Jean-Louis ${ }^{3}$, Nge Okwe Augustin ${ }^{4}$

\footnotetext{
${ }^{1}$ Service des Urgences, CHU de Brazzaville, Brazzaville, Congo

${ }^{2}$ Faculty of Health Sciences, Walter Sisulu University, Eastern Cape, South Africa

${ }^{3}$ Service de cardiologie et Médecine Interne, CHU de Brazzaville, Brazzaville, Congo
} \\ ${ }^{4}$ Biostatistics Unit, Lomo Medical Center and Heart of Africa Center of Cardiology, Kinshasa, Congo \\ Email: longombenza@gmail.com
}

Received 18 November 2013; revised 22 December 2013; accepted 31 December 2013

Copyright (c) 2014 Gombet Thierry et al. This is an open access article distributed under the Creative Commons Attribution License, which permits unrestricted use, distribution, and reproduction in any medium, provided the original work is properly cited. In accordance of the Creative Commons Attribution License all Copyrights (C) 2014 are reserved for SCIRP and the owner of the intellectual property Gombet Thierry et al. All Copyright (c) 2014 are guarded by law and by SCIRP as a guardian.

\section{ABSTRACT}

Background: Aim: Congolese Bank employees are often inactive without valid information on the burden of dysglycemia and cardiometabolic risk. This study aims to assess the prevalence rates of diabetes mellitus (DM) and pre-diabetes and to identify the environmental, genetic and cardiometabolic risk factors associated with Type 2 diabetes mellitus (T2DM) and pre-diabetes among Congolese bank employees. Methods: In representative 126 bank employees from Brazzaville, Congo, Central Africa, Abdominal obesity, dyslipidemia and metabolic syndrome (MetS) were defined by IDF for Europe, NCEP-ATPIII and IDF criteria modified for Central Africa. Projected high 10-year total risk of coronary heart disease (CHD) $\geq \mathbf{2 0} \%$ was calculated using Framingham scores. Results: Out of the employees, $16 \%$ and $21.4 \%$ had DM and pre-diabetes, respectively. The rate of T2DM among diabetics was estimated $90 \%$. Aging, high total cholesterol, high LDL-cholesterol, high conicity index and longer urban residence after migration were significantly associated with pre-diabetes. Physical inactivity, smoking, excessive alcohol intake, abdominal obesity, female gender, low HDL-C, hypertension, CHD, projected high 10-year total CHD risk, age $\geq 55$ years, urban residence, Southern area residence, high socioeconomic status, non married status, MetS/NCEP, MetS/IDF for Europe and MetS/IDF for Africa were significantly associated with T2DM.MetS/IDF for Af-

\footnotetext{
*Corresponding author.
}

rica was the only independent determinant of T2DM. Conclusion: Urgent prevention and intervention programme are needed to curb the alarming increase in DM, T2DM, pre-diabetes.

\section{KEYWORDS}

Workplace; Diabetes Mellitus Pre-Diabetes;

Cardiovascular Risk; Brazzaville

\section{INTRODUCTION}

Diabetes mellitus (DM) is a metabolic disorder characterized by chronic hyperglycaemia resulting from defects of insulin secretion, insulin action, or a combination of both [1]. Epidemic prevalence rates (age-adjusted or crude) of DM are currently observed in adult populations of Central Africa: $14.2 \%$ - 25.3\% in urban and rural areas of Kinshasa Hinterland (DR Congo) [2-4]. This contributes to the largest proportion from developing countries [5-7] on the global DM epidemic. Indeed, it is estimated that the current prevalence of 246 million diabetics throughout the world will increase to 380-500 million diabetics by 2030 [8].

As reported in both developed and other developing countries [5-7,9-11], the rising prevalence of DM in Central Africa is chiefly attributed to urbanization (industrialization and westernization/acculturation), dramatic increase in the prevalence of diabesity (Type 2 diabetes [T2DM] and obesity), sanitary (demographic, epidemiologic and nutrition) transitions, lifestyle changes 
(physical inactivity, smoking, high alcohol intake, low fruits/vegetables intake, high animal/protein intake), rural-urban migration, and social inequalities [2-4]. Interactions between environmental (ecologic, societal) and genetic (non modifiable: sex, age, family history) factors may explain the markedly high differences in DM prevalence between various populations and individuals exposed and not exposed to an obesogenic environment [11]. The very high level of metabolic disorders may be explained by physical inactivity, nutrition transition and epidemiological transition.

Recent epidemiological findings suggest that daily sitting time or low non exercise activity levels may have a significant direct association with obesity, metabolic syndrome, T2DM and cardiovascular disease (CVD) in both industrialized general and working populations [12,13]. Indeed, DM and CVD constitute the two sides of a same coin: DM is an equivalent of coronary heart disease (CHD); conversely CHD is associated with DM or prediabetes [14], a non-diabetic hyperglycaemia. T2DM is associated with metabolic syndrome (MetS) a cluster of many cardiometabolic components) which promotes microvascular and macrovascular complications in Central African diabetics [15]. However, working communitybased data on DM are still rare in the African region. The only study published in 2001 comes from South Africa with low crude (2.45\%) and age-adjusted (4.5\%) DM prevalence among black factory workers [16].

The nature of the jobs of bank employees in Brazzaville, capital of Republic of Congo (Central Africa), is defined by sedentary and western life style after ruralurban migration. The lack of integration of DM and CVD screening and prevention programmes into the existing occupational medical services in Central Africa in general and in Brazzaville in particular, urged us to conduct this survey. Indeed, in setting with established, coordinated and multidisciplinary occupational medical programmes, it is easy to intervene efficiently to reduce the suspected burden of non-communicable and chronic diseases (hypertension, DM, CVD) and their risk factors. We hypothesize, therefore, that DM, T2DM, pre-diabetes and other risk factors of CHD are epidemic.

In view of the above, the objectives of this study were to test the present hypothesis, to assess the prevalence rates of DM types and pre-diabetes, and to identify the environmental genetic and cardiometabolic risk associated with T2DM and pre-diabetes among bank employees.

\section{RESEARCH DESIGN AND METHODS}

This observational and cross-sectional study was carried out between $1^{\text {st }}$ and $30^{\text {th }}$ December, 2008 during the annual health examination mandated by Law.
Eligible participants were 1466 black and inactive employees working more than one year in any bank of Brazzaville. Their sitting jobs included maintenance, security, driving, clerical, management and administrative tasks. A $10 \%(\mathrm{n}=147)$ simple random sample drawn from the list of the eligible participants was invited to participate in after using a personal letter. The invitation letter requested them to attend the designated survey centre on a particular date, fasting between 7:30 PM and 9:00 AM. They were informed that snacks would be provided on the study centre. Interviews were trained before data collection.

\subsection{Ethical Issues}

Participants were free to participate in and gave informed written consent. The protocol of the survey was reviewed and approved by the research and ethical board in the Faculty of Health Sciences of the Marien Ngouabi University, Brazzaville. Confidentiality and anonymity of every participant was maintained and all data were kept private according to Helsinki II Declaration. Employees with detected DM and pre-diabetes were referred to the occupational Centre for cardiovascular prevention, pharmacological management or further investigation, if necessary.

\subsection{Data Collection}

Details on demography (age, sex, marital status, ruralurban migration, duration in town after migration), geographic site of residence (Northern, Central, Southern, urban versus (vs.) rural areas in Brazzaville Hinterland), medical history, socioeconomic status (monthly salary in FCFA), levels of physical activity, cigarette smoking and alcohol intake were filled in pre-coded, structured and standardized questionnaires.

Height was measured to the nearest centimetre using a wall stadiometer with the participant standing erect. Weight was measured to nearest $0.1 \mathrm{~kg}$ using a weekly calibrated balance beam scale (Soenle-Waagen GmGh Co, Murrhardt, Germany). Body mass index (BMI) was calculated as weight in kilograms squared $\left(\mathrm{Kg} / \mathrm{m}^{2}\right)$. Waist circumference (WC), the smallest girth between the coastal margin and the iliac crest, was measured to the nearest $0.5 \mathrm{~cm}$ using a standard flexible and non-distensible tape and avoiding exertion of pressure on the tissue, with the participant standing up right, after gentle expiration. Standardized protocols were used to measure both body weight, height and WC [17-19] with appropriate validation and quality-control procedures.

Systolic blood pressure (SBP) and diastolic blood pressure (DBP) were measured from the right arm of the seated participant after five minutes rest and were recorded to the nearest $2 \mathrm{mmHg}$ using a standard and 
weekly calibrated mercury sphygmomanometer with the upper arm (at least 2/3 of the upper arm according to the American Heart Association guidelines).The $1^{\text {st }}$ and $5^{\text {th }}$ Korotkoff sounds corresponded to SBP and DBP, respectively. Three measurements were used in the analysis.

Blood samples were drawn bay venopuncture in the morning and kept in ice until plasma or serum was separated. For known diabetic cases, fasting blood plasma glucose (FPG) and 2-h post prandial (regular meal) blood glucose were measured. Others underwent a standard oral glucose tolerance test (OGTT) [20]. Plasma for glucose collected in fluoride oxalate was separated within 2 $\mathrm{h}$ and assayed by glucose-oxidase peroxidise method using Hospitex Diagnostic Autoanalyzer (Florence, Italie). Serum creatinin, uric acid, total cholesterol (TC), high density lipoprotein (HDL)-C and low density lipoprotein (LDL)-C were assayed using automatic standard routine enzymatic methods and commercially kits (Biométrieux, Marcy l'Etoile, France). The coefficients of variation were $<2 \%$.

\subsection{Definitions}

Genetic and non modifiable factors included sex, age, ethnicity (Bakongo as majority vs. Bangala as minority) and family history of DM. Environmental factors were defined by areas and cities with electricity and water structures vs. rural areas without sanitation and geographic site of residence (Northern Brazzaville) with recent migration from Bangala ethnic group from the North-East of the country, Central Brazzaville with cosmopolite and multi-ethnic groups, and Southern Brazzaville with older migrations for homogeneous Bakongo ethnic group, having longer acculturation from Portuguese and French people. Westernization/acculturation was defined by longer duration of living in Brazzaville after rural-urban migration.

Socioeconomic status (SES) was defined by the Tertiles of the monthly salary: low SES (Tertile I < 500,000 FCFA), moderate SES (Tertile II: 500,000 - 700,000 FCFA) and high SES (Tertile III $\geq 900,000$ FCFA).

Work- and urbanization-related lifestyle behaviours included regular cigarette smoking (one or more cigarettes per day), excessive alcohol intake ( $\geq 30 \mathrm{~g}$ of ethanol or $\geq 4$ drinks per day vs. moderate 1 - $30 \mathrm{~g}$ ethanol or 1 - 3 drinks per day and abstainers: 0 g ethanol or 0 drink per day) and physical inactivity ( $<60$ min: median continuous index derived from time of exercise as recently defined among African workers [21].

Diagnosis of DM was established according to World Health Organization (WHO) criteria [1]: when FPG was $\geq 126 \mathrm{mg} / \mathrm{dL}(\geq 7 \mathrm{mmol} / \mathrm{L})$ or when 2-h OGTT glucose was $\geq 200 \mathrm{mg} / \mathrm{dL}(\geq 11.1 \mathrm{mmol} / \mathrm{L})$ or when the partici- pants had a known DM and treatment was ongoing. Impaired fasting glucose (IFG $=$ FPG $\geq 100 \mathrm{mg} / \mathrm{dL}$ or 5.6 $\mathrm{mmol} / \mathrm{L}$ and $<126 \mathrm{mg} / \mathrm{dL}$ or $7 \mathrm{mmol} / \mathrm{L})$ and impaired glucose tolerance $(\mathrm{IGT}=\mathrm{OGTT} \geq 140 \mathrm{mg} / \mathrm{dL}$ or 7.8 $\mathrm{mmol} / \mathrm{L}$ and $<200 \mathrm{mg} / \mathrm{dL}$ or $11.1 \mathrm{mmol} / \mathrm{L}$ ) defined prediabetes [22]. T2DM was diagnosed in participants with $\mathrm{DM}$ onset at age $\geq 40$ years, without malnutrition, nondependent on insulin therapy, earlier development of macrovascular/microvascular complication and ketoacidosis seldom as recently documented in Central Africans [4]. Types IB, IA and undetermined DM were also derived by the statistically derived syntaxes for Central Africans [4] as fasting blood insulin and C-peptide are not usually available in Africa to discriminate T2DM. Cardiometabolic risk is a global concept including obesity, hypertension, dyslipidemia, CHD, stroke and peripheral artery disease.

Total overweight/obesity was defined by BMI $\geq 25$ $\mathrm{kg} / \mathrm{m}$ [2] according to WHO criteria [19]. Abdominal obesity was defined according to International Diabetes Federation (IDF) criteria for Europe [23], IDF criteria modified for Central Africa [24] and NCEP-ATPIII [25].

Abdominal obesity defined according to IDF criteria for Central Africa, named also clinical insulin resistance, is considered as a surrogate (proxy) of insulin resistance derived by HOMA model in these Central Africans [24]. Both WC and conicity index [26] were considered as the surrogates of Central adiposity (abdominal fat distribution). The conicity index (WC in $\mathrm{m} / 0.109 \sqrt{\text { weight }}$ in $\mathrm{kg} /$ height in $\mathrm{m}$ ), is a validated simple non-invasive computation that does not require measurement of hip circumference to define Central adiposity. The conicity index is also significantly associated with atherosclerosis in Central African diabetes [27] and in general population of Western world [28].

Three operational definitions of MetS were used as follows. According to IDF criteria for Europe [23], MetS was diagnosed by WC $\geq 94 \mathrm{~cm}$ for men, WC $\geq 80 \mathrm{~cm}$ for women plus two or more of the following: $\mathrm{TG} \geq 150$ $\mathrm{mg} / \mathrm{dL}(1.7 \mathrm{mmol} / \mathrm{L})$, specific treatment for this lipid abnormalities, reduced concentration of HDL-C $<40$ $\mathrm{mg} / \mathrm{dL}(1.03 \mathrm{mmol} / \mathrm{L})$ in men and $<50 \mathrm{mg} / \mathrm{dL}(1.29$ $\mathrm{mmol} / \mathrm{L}$ ) in women or specific treatment for this lipid abnormality, SBP $\geq 130 \mathrm{mmHg}$ or $\mathrm{DBP} \geq 85 \mathrm{mmHg}$ or treatment of previous diagnosed hypertension, and FPG $\geq 100 \mathrm{mg} / \mathrm{dL}(5.6 \mathrm{mmol} / \mathrm{L})$ or previously diagnosed T2DM. According to IDF criteria for Central Africa [24], MetS was defined by $\mathrm{WC} \geq 94 \mathrm{~cm}$ for both men and women plus the other features of IDF for Europe [23]. According to the NCEP-ATPIII report [25], MetS was diagnosed by $\mathrm{WC} \geq 102 \mathrm{~cm}$ for men, $\mathrm{WC} \geq 88 \mathrm{~cm}$ for women, plus the other criteria defined by IDF for Europe.

Hypertension was defined according to the Joint National Committee (JNC)7 criteria as having an untreated 
SBP greater than or equal to $140 \mathrm{mmHg}$ or DBP greater than or equal to $90 \mathrm{mmHg}$ or being on medication for hypertension [29]. High blood pressure (BP) included known (aware) and unknown (detected, unaware) hypertension with $\mathrm{BP} \geq 140 / 90 \mathrm{mmHg}$ at the survey examination.

Since the Framingham scores were developed to estimate risk in persons without CHD, participants with physician-diagnosed CHD were not considered in the Framingham equation. We determined employees' 10year total CHD risk using the equations published by the Framingham off spring study [30]. Total CHD risk suggested a higher probability of onset of angina pectoris, unstable angina, myocardial infarction and sudden death [30,31]. Age in years, gender, SBP in $\mathrm{mmHg}$, CT/HDLC ratio, smoking status (yes vs. no), DM (yes vs. no), and left ventricular hypertrophy (LVH using Sokolow criterion from electrocardiogram) at the time of the survey were used as the risk factors in the Framingham equations. High risk of 10-year CHD was defined by the Second Joint Task Force of European and other societies on coronary prevention [32].

Particular pattern of HDL-C stratification in Central black Africans was defined by both HDL-C $<40 \mathrm{mg} / \mathrm{dL}$ and HDL-C $\geq 75 \mathrm{mg} / \mathrm{dL}$, established risk factors of MetS and CHD [33].

\subsection{Statistical Methods}

Data were summarized by calculating means \pm SD for continuous variables and proportions (\%) for categorical variables. Chi-square test was used to compare proportions while Student t-test served to compare means between groups (T2DM vs. non diabetics, pre-diabetes vs. non diabetics). $\mathrm{P}$ for trend was calculated to show any biological (dose-response effect) relationship between SES categories, geographic sites of residence, stratification of HDL-C (<40 mg/dL, $40-74.9 \mathrm{mg} / \mathrm{dL}) \geq 75 \mathrm{mg} / \mathrm{dL}$ [33] and T2DM. Odds ratios (OR) were calculated with 95\% confidence intervals (CI) using univariate (contingency table) and multivariate (logistic regression) analyses to define any association between potential risk factors, independent determinants and T2DM, respectively.

A P-value $<0.05$ was considered as statistically significant. All data analyses were performed with the SPSS package for Windows version 13.0 (SPSS Inc, Chicago, Illinois, USA).

\section{RESULTS}

The prevalence rates of dysglycemia categories in the study population were particularly high: $16 \%$ with DM $(\mathrm{n}=20)$ and $21.4 \%$ with pre-diabetes $(\mathrm{n}=27)$. Among diabetics, $10 \%$ of diabetics $(n=2)$ including 1 with Type 1 A DM and 1 with Type 1 B DM, had known Type
1DM vs. 90\% $(\mathrm{n}=18)$ with T2DM but unknown DM. Among pre-diabetics, 15 had IFG and 12 had IGT. Thus, in the total population, $11.9 \%$ had IFG and 9.5 had IGT.

Tables 1 and 2 show epidemic categorical and continuous values of other CVD risk factors in general and those related to gender, urbanization/Westernization and acculturation, sedentary nature of the jobs and lifestyle changes. Compared to male employees, females never smoked, had similar $(\mathrm{P}>0.05)$ values of age, WC, conicity index, SBP, DBP, HDL-C, MetS/IDF Central Africa, abdominal obesity defined by IDF with Central Africa and CHD, but lower $(\mathrm{P}<0.05)$ values of excessive alcohol intake and triglycerides. However, females had higher and significant $(\mathrm{P}<0.05)$ levels of physical inactivity, uncontrolled hypertension, T2DM, overweight/ obesity, abdominal obesity according to NCEP-ATPIII and IDF for Europe, heart rate, BMI, total cholesterol and LDL-C.

Employees with pre-diabetes were older and had higher levels of total cholesterol, LDL-C, conicity index and rural-urban migration duration (westernization than their non-diabetic counterparts (Table 3). Increase in BMI, WC, SBP, DBP and triglycerides as well the decrease in HDL-C were not significantly associated with the presence of pre-diabetes.

There was a significant and dose-response (linear biologic gradient) relationship between levels of aging $(\mathrm{P}$ for trend $=0.005$ ), SES (P for trend $=0.016$ ), geographic site of residence $(\mathrm{P}$ for trend $=0.025$ ) and T2DM prevalence (Figures 1-3). Non married status (90\% being women), urban residence, MetS according to NCEPATPIII, IDF for Europe and IDF modified for Central Africa were also identified as significant risk factors of T2DM (Table 4). All employees with T2DM had CHD, were physically inactive (absolute risk of 100\%) and drinking excessive alcohol (absolute risk of 100\%). All male smokers had T2DM (absolute risk of 100\%). There was no significant $(\mathrm{P}>0.05)$ association between total obesity defined by BMI, individual lipidic component (total cholesterol, triglycerides, HDL-C, LDL-C) disorder and the presence of T2DM (data not shown). However abdominal obesity defined by IDF Europe criteria $(\mathrm{OR}=45$ 95\%CI 8 - 132; $\mathrm{P}<0.0001)$; NCEP-ATPIII (OR = 18 95\% 4 - 82; P $<0.0001)$, and IDF for Central Africa (OR = 85.9 95ùCI 9.9 - 124; $\mathrm{P}<0.0001)$ was significantly associated with the presence of T2DM. The highest risk of T2DM was due to both abdominal obesity and MetS defined by IDF criteria modified for Central Africa.

\section{Cardiometabolic Consequences of T2DM}

The increase in the prevalence rates of T2DM was significantly proportional with the rise of the levels of SBP 
Table 1. T2DM, CHD and other cardiovascular risk factors in the study population, 70 men and 56 women.

\begin{tabular}{|c|c|c|c|c|}
\hline Variables & All $n=126$ & Men & Women & $\mathbf{P}$ \\
\hline Smoking & 3.2 & 5.7 & 0 & $<0.05$ \\
\hline Excessive alcohol & 33.6 & 44.3 & 21.4 & 0.007 \\
\hline Physical inactivity & 85.7 & 75.7 & 98.2 & $<0.0001$ \\
\hline Hypertension/uncontrolled & 26.2 & 17.1 & 37.5 & $<0.01$ \\
\hline T2DM & 14.3 & 11.4 & 17.9 & 0.049 \\
\hline Overweight/total obesity & 65.1 & 55 & 75 & $<0.0001$ \\
\hline \multicolumn{5}{|l|}{ Abdominal obesity } \\
\hline • NCEP-ATPIII & 39.9 & 21.4 & 62.5 & $<0.0001$ \\
\hline - IDF Europe & 63.5 & 48 & 80 & $<0.0001$ \\
\hline - IDF Central Africa & 43.7 & 42.9 & 44.6 & 0.841 \\
\hline \multicolumn{5}{|l|}{ MetS } \\
\hline • NCEP-ATPIII & 8.7 & 2.9 & 16.1 & 0.009 \\
\hline - IDF Europe & 14.3 & 8.6 & 21.4 & 0.040 \\
\hline • IDF Central Africa & 15.9 & 11.4 & 21.4 & 0.127 \\
\hline CHD & 15.1 & 15.2 & 15 & 0.890 \\
\hline
\end{tabular}

Table 2. Continuous characteristics in all, male and female employees.

\begin{tabular}{ccccc}
\hline Variables & All & Men & Women & P \\
\hline Age (years) & $42 \pm 9$ & $41 \pm 9$ & $43 \pm 9$ & 0.145 \\
Heart rate (bpm) & $68 \pm 12$ & $65 \pm 10$ & $71 \pm 12$ & 0.004 \\
BMI (Kg/m $^{2}$ & $27.2 \pm 5.1$ & $26 \pm 4.4$ & $28.6 \pm 5.6$ & 0.004 \\
WC (cm) & $92.1 \pm 12.3$ & $91.8 \pm 12.3$ & $92.6 \pm 12.5$ & 0.714 \\
Conicity index & $1.2 \pm 0.1$ & $1.23 \pm 0.1$ & $1.23 \pm 0.1$ & 0.891 \\
SBP (mmHg) & $141.4 \pm 23.2$ & $141.2 \pm 24.2$ & $141.7 \pm 22.1$ & 0.898 \\
DBP (mmHg) & $87.1 \pm 13.6$ & $86.4 \pm 14.8$ & $88 \pm 12.1$ & 0.503 \\
HDL-C (mg/dL) & $80.5 \pm 31.6$ & $75 \pm 40.7$ & $85 \pm 28.7$ & 0.348 \\
Total cholesterol (mg/dL) & $200.1 \pm 48$ & $190.6 \pm 43.6$ & $213.5 \pm 50.9$ & 0.014 \\
Triglycerides (mg/dL) & $75.9 \pm 39.1$ & $83.8 \pm 43.6$ & $64.9 \pm 29.6$ & 0.013 \\
LDL-C (mg/dL) & $105 \pm 61.5$ & $93.7 \pm 57$ & $121.1 \pm 64.8$ & 0.023 \\
\hline
\end{tabular}

Table 3. Relationship between anthropometry, blood pressure, lipid profile, rural-urban migration duration and pre-diabetes.

\begin{tabular}{|c|c|c|c|}
\hline \multirow{2}{*}{ Variables } & \multicolumn{2}{|c|}{ Pre-diabetes } & \multirow{2}{*}{$\mathbf{P}$} \\
\hline & Yes $(n=27)$ & No $(n=79)$ & \\
\hline Age (years) & $46 \pm 8$ & $42 \pm 8$ & 0.020 \\
\hline BMI $\left(\mathrm{Kg} / \mathrm{m}^{2}\right)$ & $28.6 \pm 5.1$ & $26.8 \pm 5.1$ & 0.137 \\
\hline $\mathrm{WC}(\mathrm{cm})$ & $96.1 \pm 11.4$ & $91.8 \pm 12.8$ & 0.140 \\
\hline Total cholesterol (mg/dL) & $228.9 \pm 61.4$ & $192.3 \pm 40.3$ & $<0.001$ \\
\hline HDL-C (mg/dL) & $75 \pm 40.7$ & $82 \pm 28.7$ & 0.348 \\
\hline Triglycerides (mg/dL) & $87.7 \pm 36.2$ & $72.7 \pm 39.8$ & 0.105 \\
\hline Rural-urban migration duration (years) & $11.1 \pm 12.2$ & $5.9 \pm 9$ & 0.036 \\
\hline LDL-C (mg/dL) & $136.3 \pm 67.3$ & $96.4 \pm 57.4$ & 0.005 \\
\hline Conicity index & $1.3 \pm 0.08$ & $1.2 \pm 0.07$ & 0.046 \\
\hline SBP (mmHg) & $149.5 \pm 22.1$ & $140.5 \pm 23.9$ & 0.105 \\
\hline DBP (mmHg) & $91.2 \pm 11.5$ & $86.8 \pm 14.3$ & 0.181 \\
\hline
\end{tabular}

and DBP, respectively: 0\% $(n=0 / 22)$ for SBP $<120$ $\mathrm{mmHg}, 9.5 \%(\mathrm{n}=4 / 42)$ for SBP $=120-139 \mathrm{mmHg}$, and $25.8 \%(n=16 / 62)$ for SBP $>140 \mathrm{mmHg}$ with $\mathrm{P}$ for trend
$=0.035$; and 4.7\% $(\mathrm{n}=2 / 43)$ for $\mathrm{DBP}<80 \mathrm{mmHg}, 15 \%$ $(\mathrm{n}=6 / 40)$ for DBP $=80-89 \mathrm{mmHg}$, and $27.9 \%(\mathrm{n}=$ 12/43) for $\mathrm{DBP}>90 \mathrm{mmHg}$ with $\mathrm{P}$ for trend $=0.047$. 


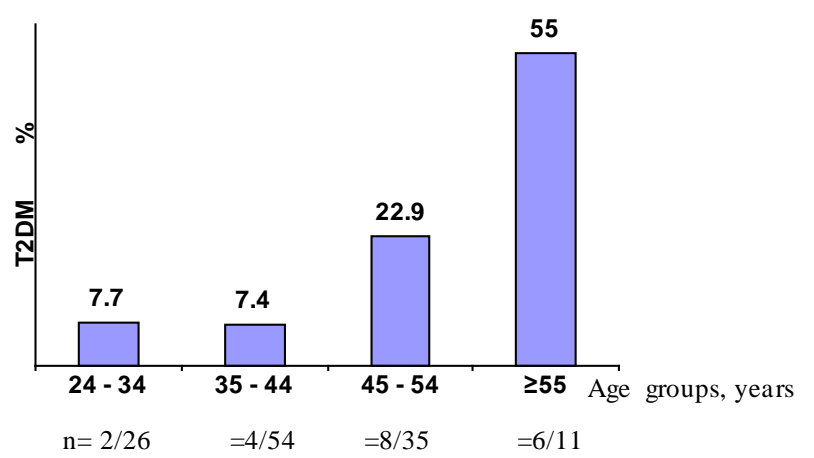

Figure 1. Exponential curve of T2DM distribution.

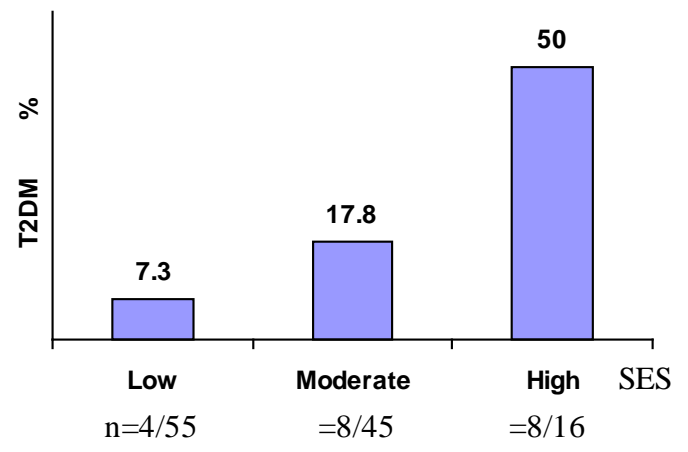

Figure 2. Relationship between Type 2 diabetes (T2DM) prevalence and socio-economic status (SES).

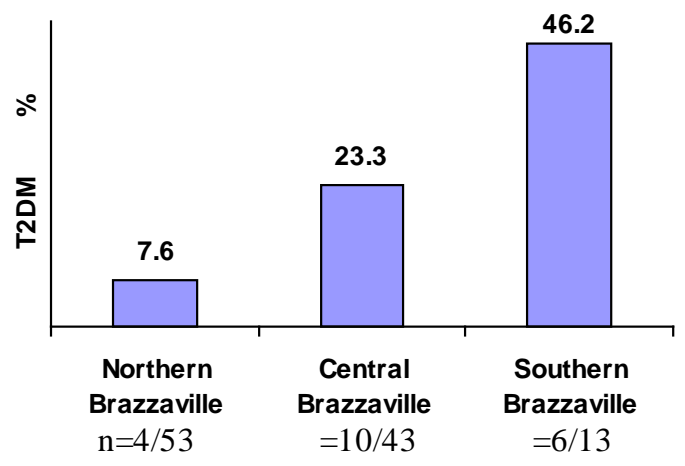

Figure 3. North-South gradient of Type 2 diabetes (T2DM) distribution.

The highest rates of T2DM were at the levels of BP defining hypertension. There was a significant association between T2DM and hypertension; the risk of unknown hypertension $(42.4 \% n=14 / 33$, OR $=8.195 \%$ CI 2 33.5; $\mathrm{P}<0.001)$ being higher than that of known hypertension $(28.6 \% \mathrm{n}=16 / 56, \mathrm{OR}=5.7$ 95\%CI 1.2 - 27.9; $\mathrm{P}$ $=0.018$ ) conferred by T2DM in comparison with absence of DM $(6 \% n=4 / 70)$.

T2DM was more $(\mathrm{P}=0.022)$ prevalent among employees with high 10-year total CHD risk using Framingham scores $(50 \% n=6 / 12)$ than among employees with low CHD risk $(12.3 \% \mathrm{n}=14 / 114)$.

No participant was aware of family history of DM, hypertension, CHD, premature CVD, as well as personal history of viral diseases and protein malnutrition in childhood or auto-immune diseases.

After HDL-C stratification, 24.6\% $(\mathrm{n}=31)$ and $19.1 \%$ ( $n=24$ ) had low HDL-C and very HDL-C, respectively.

The first logistic model identified MetS defined by IDF criteria modified for Central Africa as the only independent and significant determinant ( $\mathrm{OR}=56.8$ 95\% CI 16.4 - 103; $\mathrm{P}<0.0001$ ) of the presence of T2DM after adjusting for gender, age, HDL-C stratification, SES, alcohol intake, smoking, geographic site, duration of migration, TC, and LDL-C.

Aging (age $\geq 45$ years vs. age $<45$ years) was identified as the only independent and significant determinant (OR = 4.8 95\% CI 1.1 - 20.6; P = 0.037) of T2DM when MetS was replaced by its individual components in the second logistic regression model.

\section{DISCUSSION}

The alarming rates of DM (16\%), pre-diabetes (21.4\%) and T2DM among diabetics (90\%) in these bank employees confirm the current epidemic of DM and its prestate at global [5-8,12,13] and regional [2-4] levels. We are now far away from prevalence of DM estimated $1 \%-13 \%$ in previous general-and working-African populations $[16,34,35]$. We confirmed the hypothesis of epidemic of cardiovascular risk factors as well we confirmed specificities of anthropometry and lipid profiles in central Africans [3,4,15,21,24,33].

The present study outlines the importance of interactions of environmental factors and genetic (non modifiable risk factors in the pathogenesis of DM and T2DM. Lifestyle changes increasing in abdominal obesity, urbanization after rural-migration, increasing T2DM, and changes in employees demographics have together contributed to a dramatic increase in DM, T2DM and other CVD risk factors. The dramatic increasing of T2DM prevalence is also a consequence of an impending occupational health services crisis, a lack of community involvement, globalization, westernization, social inequalities and recent socio-political and military crisis in Brazzaville.

A significant female preponderance of T2DM, physical inactivity, non-married status, hypertension, overweight/total obesity, MetS and abdominal obesity defined by International criteria, heart rate, total cholesterol and LDL-C was shown in this working population. This may be explained by a double mental stress faced by women in comparison with men: combination of job strain, mental stress for non married and family-related stress for married. Excessive of DM was also reported among rural women in Mali [36], while an equal gender distribution of DM is observed in Kinshasa (DR Congo) [3,4], 
Table 4. Other risk of Type 2 diabetes (T2DM) among bank employees.

\begin{tabular}{|c|c|c|c|}
\hline Risk factors & Prevalence of T2DM \% (n) & OR (95\%CI) & $\mathbf{p}$ \\
\hline \multicolumn{4}{|l|}{ Marital status } \\
\hline • Non married & $30.8(n=8 / 26)$ & $\begin{array}{c}32.6 \\
(6-39)\end{array}$ & $<0.0001$ \\
\hline - Married & $12(n=12 / 100)$ & & \\
\hline \multicolumn{4}{|l|}{ Residence } \\
\hline - Urban & $28.6(n=16 / 56)$ & $\begin{array}{c}4.3 \\
(1.9-8.2)\end{array}$ & $<0.0001$ \\
\hline - Semi-rural & $7.6(n=4 / 53)$ & & \\
\hline \multicolumn{4}{|l|}{ MetS/NCEP-ATPIII } \\
\hline • Yes & $90.9(n=10 / 11)$ & $\begin{array}{c}18.3 \\
(4.1-81.1)\end{array}$ & $<0.0001$ \\
\hline • No & $8.7(\mathrm{n}=10 / 115)$ & & \\
\hline \multicolumn{4}{|l|}{ MetS/IDF Europe } \\
\hline • Yes & $88.9(n=16 / 18)$ & $\begin{array}{c}42.4 \\
(7.9-127.4)\end{array}$ & $<0.0001$ \\
\hline • No & $3.7(n=4 / 108)$ & & \\
\hline \multicolumn{4}{|l|}{ MetS/IDF Central Africa } \\
\hline • Yes & $90(n=18 / 20)$ & $\begin{array}{c}85.1 \\
(9.9-174.2)\end{array}$ & $<0.0001$ \\
\hline • No & $1.9(n=2 / 106)$ & & \\
\hline
\end{tabular}

and global estimates [37], but a male preponderance in rural Cameroonians [38].

T2DM prevalence in these bank employees increased significantly with age as observed in population from Kinshasa Hinterland [4]. This situation is a result of demographic and epidemiological transition [11,38,39] in developing countries [40]. The onset of T2DM in older ages ( $\geq 45$ years) is characteristic for developed countries.

The present study supports the existence of the prominent role of environmental "trigger" factors such as urban residence, living in Southern area, high SES, physical inactivity, smoking and high alcohol intake on genetic influence (no family history of DM reported in the present study). Affluent Congolese in general and Bakongo ethnic group with long tradition of westernization, acculturation and migration in particular are mostly settled in urban and Southern areas of Brazzaville. Civil war during the last decade, based in the Southern area of Brazzaville, may be an other environmental "trigger" factor.

The present findings confirm the limited role of BMI (overweight/total obesity) in predicting T2DM [4,41] as well hypertension [21] in general and working African populations. Indeed, BMI measures total body mass and both fat and lean mass, whereas WC and conicity index are used as proxy measures for fat distribution (abdominal obesity) [24,26]. Furthermore, higher levels of WC, conicity index, abdominal obesity and MetS were significantly and individually associated with T2DM but not with gender and pre-diabetes. Other specificities in this study were the normal range of lipid profiles and the low rates of MetS usually reported in the African populationsand cardiovascular patients-based studies [33,42,43]. The main observations in these findings were related to the reverse epidemiology. Only increases in total cholesterol and LDL-C were significantly associated with prediabetes, while traditionally defined disorders of total cholesterol, HDL-C, LDL-C and triglycerides were not significantly related to the presence of T2DM. Very few bank employees had low HDL-C and very high HDL-C, whereas a curvilinear relationship has been observed between CVD, chronic renal failure, Helicobacter pylori-induced gastritis (a well established CVD risk factor) and HDL-C stratification in Central Africans with congestive heart failure [33]. Elevated HDL-C and less atherogenic dyslipidemia is reported in Japanese men with deficiency in cholesterol-ester transfer protein (CETP) [44]. Malnutrition, red wine consumption often observed in this former French colony, walking, and possible inaccurate HDL-C dosage may explain the elevated levels of HDL-C. Indeed the mean levels of HDL-C in the study population, men and women were in the normal range, respectively.

Dehout et al. [45] have documented an earlier T2DM onset with concurrent insulin resistance and earlier loss of insulin secretion.

\section{Clinical and Public Health Perspectives}

What is evident from our findings is that bank employees with T2DM are at increased risk of hypertension and CHD. Moreover, this increased CVD risk is apparent even before clinical diagnosis of T2DM (pre-diabetes) as reported in developed countries [46]. Our data agree with 
experts of NCEP-ATPIII [25] who consider DM as a coronary risk equivalent. Other findings, however, the T2DM-related increased CHD risk is not as great as in those persons with CHD alone [47].

Discrepancies in cut-points of overall obesity, abdominal adiposity and dyslipidemia have a profound effect on prevalence estimates of CVD from the public health point of view. The current WHO [19], IDF [23] and NCEP-ATPIII [25] cut-points could underestimate overall obesity, abdominal obesity and lipid disorders in these black employees as demonstrated in an Arab population of the middle East [48]. While it is useful to have ethnic-specific cut-points for various obesity indices: $\mathrm{BMI} \geq$ $23 \mathrm{~kg} / \mathrm{m}^{2}$, WC94 cm, conicity index, HDL-C $<40 \mathrm{mg} / \mathrm{dL}$ and HDL-C $\geq 75 \mathrm{mg} / \mathrm{dL}$ will result in an increase in detecting Central Africans at higher cardiometabolic risk.

The present high prevalences of pre-diabetes, aging, MetS and physical inactivity predict a further increase in the prevalence of T2DM in these bank employees over the next few years, consistent with the recent study of incidence of T2DM in Kinshasa Hinterland [49]. Thus, the ultimate purpose of identifying modifiable environmental risk factors for T2DM and pre-diabetes lies in the hope of primordial, primary and secondary prevention of T2DM and CVD.

There is an urgent need for health leaders, employers and employees to modify lifestyle behaviours by including exercise, smoking cessation, alcohol intake reducing to moderate level, adopting appropriate diet and combating obesity. Health promotion interventions that do not save money and application of the present recommendations could make a major to the prevention and control of DM, T2DM, CHD, and other CVD risk factors.

\section{LIMITATIONS}

Despite its cross-sectional design and small size of the study population, this study had certain strength through higher response rate, sensitization and 2-h load glucose test to diagnose DM. A multivariate analysis (logistic regression) to avoid confounding risk factors of T2DM are interrelated. Many of the lifestyle-related factors are linked with the development of obesity and hypertension associated with T2DM.

\section{CONCLUSION}

Epidemic rates of DM, T2DM (equivalent of coronary heart), pre-diabetes and cardiovascular risk factors associated with aging, urbanization, high socioeconomic status and lifestyle changes are observed. The highest risk of T2DM is determined by HDL-C $\geq 75 \mathrm{mg} / \mathrm{dL}$, physical inactivity and MetS defined by IDF criteria modified for Central Africa. Urgent implication of occupational health services is necessary for prevention and control of non communicable diseases among these bank employees.

\section{ACKNOWLEDGEMENTS}

The authors would like to thank the participants, the investigators and the bank employees in Brazzaville, Congo.

\section{REFERENCES}

[1] WHO Consultation (1999) Definition, diagnosis and classification of diabetes mellitus. Report n 99.2. World Health Organization, Geneva.

[2] Longo-Mbenza, B., Vangu Ngoma, D., Nahimana, D., Mayuku, D.M., Mbungu, F.S., Ekwanzala, F. and Beya, C. (2008) Screen detected and the WHO Stepwise approach to the prevalence and risk factors of arterial hypertension in Kinshasa. The European Journal of Cardiovascular Prevention \& Rehabilitation, 5, 503-508. http://dx.doi.org/10.1097/HJR.0b013e3282f21640

[3] On'Kin, J.B.K.L., Longo-Mbenza, B., Nge okwe, A., Ditu, M.S., Okitolonda, W. and He, J. (2008) Prevalence and risk factors of diabetes mellitus in Kinshasa Hinterland. International Journal of Diabetes and Metabolism, 16, 97-106.

[4] On’Kin, J.B.K.L., Longo-Mbenza, B., Nge okwe, A., Kangola Kabangu, N., Mbungu Fuele, S. and Milongo Dipa, G. (2008) Classification and dramatic epidemic of diabetes mellitus in Kinshasa Hinterland: The prominent role of Type 2 diabetes and lifestyle changes among Africans. Nigerian Journal of Medicine, 18, 311-320.

[5] Ramachandran, A., Mary, S., Yamuna, A., Murugesan, N. and Snehalatha, C. (2008) High prevalence of diabetes and cardiovascular risk factors associated with urbanization in India. Diabetes Care, 31, 893-898. http://dx.doi.org/10.2337/dc07-1207

[6] Sicree, R., Shaw, J. and Zimmet, P. (2006) Prevalence and projections. In Diabetes Atlas. 3rd Edition. Brussels, Belgium. International Diabetes Federation, 16-104.

[7] Zimmet, P., Alberti, K.G. and Shaw, J. (2001) Global and societal implications of the diabetes epidemic. Nature, 414, 782-787. http://dx.doi.org/10.1038/414782a

[8] Wild, S., Roglic, G., Green, A., Sicree, R. and King, H. (2004) Global prevalence of diabetes: Estimates for the year 2000 and projections for 2030. Diabetes care, 27, 1047-1053. http://dx.doi.org/10.2337/diacare.27.5.1047

[9] Fach, D., William, J., Tappy, L., Ravussin, E. and Bovet, P. (2007) Prevalence, awareness and control of diabetes in the Seychelles and relationship with excess body weight. BMC Public Health, 7, e163. http://dx.doi.org/10.1186/1471-2458-7-163

[10] Yach, D., Stickler, D. and Brownell, K.D. (2006) Epidemiologic and economic consequences of the global epidemics of obesity and diabetes. Nature Medicine, 12, 62-66. http://dx.doi.org/10.1038/nm0106-62

[11] Soderberg, S., Zimmet, P., Tuomilehto, J., de Courten, M., Dowse, G.K., Chitson, P., Gareeboo, H., Alberti, K.G. and Shaw, J.E. (2005) Increasing prevalence of Type 2 diabetes mellitus in all ethic groups in Mauritius. Dia- 
betic Medicine, 22, 61-68. http://dx.doi.org/10.1111/j.1464-5491.2005.01366.x

[12] Hamilton, M.T., Hamilton, D.G. and Zderic, T.W. (2005) Role of low energy expenditure and sitting in obesity, metabolic syndrome, Type 2 diabetes and cardiovascular disease. Diabetes, 56, 2655-2667.

http://dx.doi.org/10.2337/db07-0882

[13] Oberlinner, C., Neumann, S.M., OH, M.G. and Zober, A. (2008) Screening for pre-diabetes and diabetes in the workplace. Occupational Medicine, 58, 41-45. http://dx.doi.org/10.1093/occmed/kqm129

[14] Esc/EASD guidelines on diabetes, pre-diabetes and cardiovascular diseases: Executive summary. (2007) European Heart Journal, 28, 88-136.

[15] Longo-Mbenza, B., Ngimbi, R.M., Ngoma, D.V., Fuele, S.M. and Buassa-bu-Tsumbu, B. (2008) Risk factors of stroke among Congolese black hypertensive diabetics. Annales de Cardiologie et d'Angéiologie, 57, 37-43. http://dx.doi.org/10.1016/j.ancard.2007.08.013

[16] Erasmus, R.T., Blanco Blanco, E., Okesina, A.B., Matsha, T., Gaweta, Z. and Mesa, J.A. (2001) Prevalence of diabetes mellitus and impaired glucose tolerance in factory workers from Transkei, South Africa. South African Medical Journal, 91,157-160.

[17] Lohman, T.G., Roche, A.F. and Martorel, R. (1998) Anthropometric standardization reference manual champaign, IL. Human Kinetics, 3-8, 39-70.

[18] Wang, J., Thornton, J.C., Bari, S., Williamson, B., Gallagher, D., Heymsfield, S.B., Horlick, M., Kotler, D., Laferrere, B., Mayer, L., Pi-Sunyer, F.X. and Pierson, R.N. Jr. (2003) Comparison of waist circumference measured at four sites. The American Journal of Clinical Nutrition, 77, 379-384.

[19] World Health Organization (1998) Obesity, preventing and managing the global epidemic. Report of a WHO Consultation on obesity. WHO, Geneva.

[20] Spijkerman, A.M.W., Fuyun, M.F., Griffin, S.J., Dekker, J.M., Nijpels, G. and Warehan, N.J. (2004) The performance of a risk score as a screening test for undiagnosed hyperglycemia in ethnic minority groups. Diabetes Care, 27, 116-122. http://dx.doi.org/10.2337/diacare.27.1.116

[21] Longo-Mbenza, B., Nkoy Belila, J., Vangu Ngoma, D. and Mbungu, S. (2007) Prevalence and risk factors of arterial hypertension among urban Africans in workplace: The obsolete role of body mass index. Nigerian Journal of Medicine, 16, 42-49. http://dx.doi.org/10.4314/njm.v16i1.37280

[22] The Expert Committee on the diagnosis and classification of diabetes mellitus. (2003) Report of the expert committee on the diagnosis and classification of diabetes mellitus. Diabetes Care, 26, SE-S20.

[23] Alberti, K.G., Zimmet, P., Shaw, J. and IDF Epidemiologic Task Force Consensus Group. (2005) The metabolic syndrome: A new worldwide definition. Lancet, 366, 1059-1062. http://dx.doi.org/10.4314/njm.v16i1.37280

[24] On’Kin, J.B.K.L., Longo-Mbenza, B., Nge Okwe, A. and Kangola Kabangu, N. (2007) Survey of abdominal obesities in an adult urban population of Kinshasa, Democratic
Republic of Congo. Cardiovascular Journal of Africa, 18, 300-307.

[25] Executive Summary of the Third Report of the National Cholesterol Education Program (NCEP) expert panel on detection, evaluation and treatment of high blood cholesterol in adults (Adult treatment Panel III 2001). JAMA, 285, 2486-2497.

[26] Valdez, R., Seidl, J.C., Ahn, Y.I. and Weiss, K.M. (1992) A new index of abdominal adiposity as an indicator of risk for cardiovascular disease: A cross-population study. International Journal of Obesity, 16, 77-82.

[27] Longo-Mbenza, B., Bieleli, E., Muls, E., Vangu, N. and Ditu, M.S. (2002) The role of early hemodynamic impairment and disease duration on diabetic cardiomyopathy and hypertension in Central Africans with atherosclerosis. Journal of Diabetes and Its Complications, 16, 146-152. http://dx.doi.org/10.1016/S1056-8727(00)00129-X

[28] Ford, E.S. (2002) Does exercise reduce inflammation? Physical activity and C-reactive protein in US adults. Epidemiology, 13, 561-568. http://dx.doi.org/10.1097/00001648-200209000-00012

[29] Chobanian, A.V., Bakris, G.L., Black, H.R., Cushman, W.C., Green, L.A., Izzo Jr., J.L. (2003) The Seventh report of Joint National Committee on prevention, detection, evaluation and treatment of high blood pressure: The JNC7 Report. JAMA, 289, 2560-2572. http://dx.doi.org/10.1001/jama.289.19.2560

[30] Anderson, K.M., Wilson, P.W., Odell, P.M., Kannel, W.B. (1991) An updated coronary risk profile. A statement for health professionals. Circulation, 83, 356-362. http://dx.doi.org/10.1161/01.CIR.83.1.356

[31] Grundy, S.M., Pasternal, R., Greenland, P., Smith Jr., S. and Fuster, V. (1999) Assessment of cardiovascular risk by use of multiple-risk-factor assessment equations: A statement for healthcare professionals from the American Heart Association and the America College of cardiology. Circulation, 100, 1481-1492. http://dx.doi.org/10.1161/01.CIR.100.13.1481

[32] Prevention of coronary heart disease in clinical practice. (1998) Recommendations of the Second Joint Tak Force of European and other societies on coronary prevention. European Heart Journal, 19, 1434-503.

[33] Longo-Mbenza, B., Mambune, H.F., Kasiam, J.B., Vita, E.K., Fuele, S.M., Nsenga, J.N., Mabwa, L. and Nzuzi, V. (2007) Relationship between waist circumference and cholesterol in Central Africans with congestive heart failure. West African Journal of Medicine, 26, 183-190.

[34] Sobngwi, E., Mauvais-Jarvis, E., Vexiau, P., Mbanya, J.C. and Gautier, J.F. (2001) Diabetes in Africans. Part 1: Epidemiology and clinical specificities. Diabetes and Metabolism, 27, 628-634.

[35] Balde, N.M., Diallo, I., Balde, M.D., Barry, I.S., Kaba, L., Diallo, M.M., Kaké, A., Camara, A., Bah, D., Barry, M.M., Sangaré-Bah, M. and Maugendre, D. (2007) Diabetes and impaired fasting glucose in rural and populations in Futa Jallon (Guinea): Prevalence and associated risk factors. Diabetes Metabolism, 33, 114-120. http://dx.doi.org/10.1016/j.diabet.2006.10.001 
[36] Fisch, A., Pichard, E., Prazuck, T., Leblanc, H., Sidibe, Y. and Brucker, G. (1987) Prevalence and risk factors of diabetes mellitus in the rural region of Mali (West Africa): A practical approach. Diabetologia, 30, 859-862.

[37] King, H., Rewers, M. and WHO AD HOC Diabetes Reporting group. (1993) Global estimates for prevalence of diabetes mellitus and impaired glucose tolerance in adults. Diabetes Care, 16, 157-177. http://dx.doi.org/10.2337/diacare.16.1.157

[38] Mbanya, J.C., Ngogang, J., Salah, J.N., Minkoulou, E. and Balkau, B. (1997) Prevalence of NIDDM and impaired glucose tolerance in a rural and an urban population in Cameroon. Diabetologica, 40, 824-829. http://dx.doi.org/10.1007/s001250050755

[39] Motala, A.A. (2002) Diabetes trends in Africa. Diabetes/ Metabolism Research and Reviews, 18, S14-S20. http://dx.doi.org/10.1002/dmrr.284

[40] Bonora, E., Kiechl, S., Willeit, J., Oberhollenzer, F., Egger, G., Meigs, J.B., Bonadonna, R.C. and Muggeo, M. (2004) Population-based incidence rates and risk factors for Type 2 diabetes in white individuals. The Bruneck study. Diabetes, 53, 1782-1789. http://dx.doi.org/10.2337/diabetes.53.7.1782

[41] Lester, F.T. (1984) The clinical pattern of diabetes in Ethiopians. Diabetes Care, 7, 6-11. http://dx.doi.org/10.2337/diacare.7.1.6

[42] Fezeu, L., Balkau, B., Kengne, A.P., Sobngwi, E. and Mbanya, J.C. (2007) Metabolic syndrome in a sub-Saharan African setting: Central obesity may be the key determinant. Atherosclerosis, 193, 70-76. http://dx.doi.org/10.1016/j.atherosclerosis.2006.08.037

[43] Longo-Mbenza, B., Nkondi Nsenga, J. and Vangu Ngoma, D. (2007) Prevention of the metabolic syndrome insulin resistance and the atherosclerotic diseases in Africans infected by Helicobacter pylori infection and treated by antibiotics. International Journal of Cardiology, 121, 229-238. http://dx.doi.org/10.1016/j.ijcard.2006.12.003
[44] Zhong, S., Sharp, D.S., Grove, J.S., Bruce, C., Yano, K., Curb, J.D. and Tall, A.R. (1996) Increased coronary heart disease in Japanese-American men with mutation in the cholesterol ester transfer protein in the despite increased HDL levels. Journal of Clinical Investigation, 97, 29172923. http://dx.doi.org/10.1172/JCI118751

[45] Dehout, F., Haumont, S., Gaham, N., Amoussou Genou, K.D. and Hermans, M. (2008) Metabolic syndrome in Bantu subjects with Type 2 diabetes from sub-Saharan extraction prevalence, gender differences and HOMA-hyperbolic product. Diabetes \& Metabolic Syndrome: Clinical Research \& Reviews, 2, 5-11. http://dx.doi.org/10.1016/j.dsx.2007.11.008

[46] Hu, F.B., Stampfer, M.J., Haffner, S.M., Solomon, C.G., Willett, W.C. and Manson, J.E. (2002) Elevated risk of cardiovascular disease prior to clinical diagnosis of Type 2 diabetes. Diabetes Care, 25, 1129-1134. http://dx.doi.org/10.2337/diacare.25.7.1129

[47] Evans, J.M.M., Wang, J. and Morris, A.D. (2002) Comparison of cardiovascular risk between patients with Type 2 diabetes and those who had a myocardial infarction: Cross sectional and cohort studies. British Medical Journal, 324, 939.

http://dx.doi.org/10.1136/bmj.324.7343.939

[48] Al-Lawati, J.A., Barakat, N.M., Al-Lawati, A.M. and Mohammed, A.J. (2008) Optimal cut-points for body mass index, waist circumference and waist-to-hip ratio using the Framingham coronary heart disease risk score in an Arab population of the Middle East. Diabetes and Vascular Disease Research, 5, 304-309. http://dx.doi.org/10.3132/dvdr.2008.044

[49] Longo-Mbenza, B., Kasiam Lasi On’Kin, J.B., Nge Okwe, A., Vangu Ngoma, D. and Mbungu Fuele, S. (2010) Metabolic syndrome, aging, physical inactivity and incidence of Type 2 diabetes in general African population. Diabetes and Vascular Disease Research, 7, 28-39. http://dx.doi.org/10.1177/1479164109346362 